\title{
MICROWAVE-ASSISTED SYNTHESIS OF 1,3-DIMESITYLIMIDAZOLINIUM CHLORIDE
}

A.<smiles>[2H]C=CC=O</smiles>

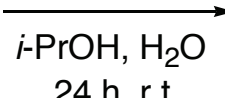<smiles>Cc1cc(C)c(N=CC=Nc2c(C)cc(C)cc2C)c(C)c1</smiles>

B.
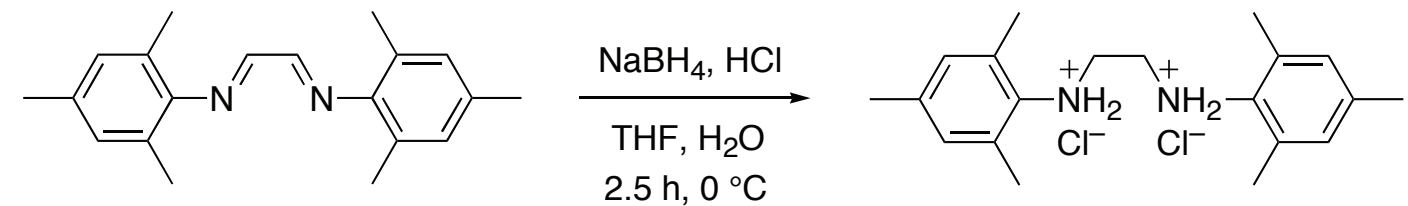

C.
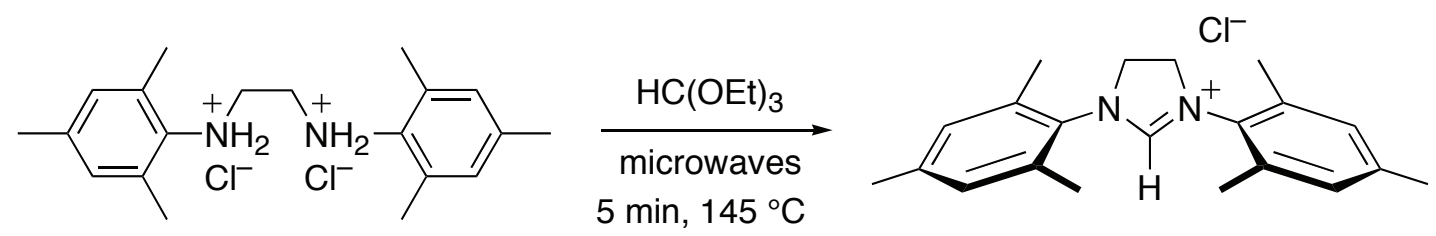

Submitted by Morgan Hans and Lionel Delaude. ${ }^{1}$

Checked by Somenath Chowdhury and Jonathan A. Ellman.

\section{Procedure}

A. N,N'-Dimesitylethylenediimine. A 500-mL, one-necked, roundbottomed flask equipped with a magnetic stirring bar and a stopper is charged with 2,4,6-trimethylaniline (40.56 g, $0.300 \mathrm{~mol}, 2.0$ equiv) and isopropyl alcohol $(150 \mathrm{~mL}$ ) (Notes 1, 2). Glyoxal (21.76 g of a $40 \%$ aqueous solution, $0.150 \mathrm{~mol}, 1.0$ equiv) is weighed in a $250-\mathrm{mL}$ Erlenmeyer flask (Note 3$)$ and further diluted with deionized water $(50 \mathrm{~mL})$ and isopropyl alcohol $(50 \mathrm{~mL})$ (Note 2$)$. This colorless mixture is briefly swirled. It is then poured into the aniline solution. The resulting solution is stirred for $24 \mathrm{~h}$ at room temperature. A bright yellow precipitate appears within a few minutes and progressively builds up. After $24 \mathrm{~h}$, the suspension is filtered through a Büchner funnel, and the precipitate is washed with deionized water $(2 \times 100$ $\mathrm{mL}$ ) (Note 4). It is spread out in a $20-\mathrm{cm}$ diameter evaporating dish and dried in an oven at $40{ }^{\circ} \mathrm{C}$ under $30 \mathrm{mmHg}$ vacuum until constant weight (Note 5) to afford $40.09 \mathrm{~g}(91 \%)$ of $N, N^{\prime}$-dimesitylethylenediimine as a bright yellow solid (Note 6). 
B. $\quad N, N^{\prime}$-Dimesitylethylenediamine Dihydrochloride. A 500-mL, twonecked, round-bottomed flask equipped with a magnetic stirring bar, a thermometer, and a solid addition funnel is charged with $N, N^{\prime}$-dimesitylethylenediimine (36.55 g, $0.125 \mathrm{~mol}, 1.0$ equiv) and tetrahydrofuran (300 $\mathrm{mL}$ ) (Note 7). The bright yellow suspension is cooled to $0{ }^{\circ} \mathrm{C}$ internal temperature using an ice-water bath before sodium borohydride (18.92 $\mathrm{g}$, 0.500 mol, 4.0 equiv) is added in one portion (Notes 8, 9). Next, concentrated hydrochloric acid $(21 \mathrm{~mL}, 0.25 \mathrm{~mol}, 2.0$ equiv) is added dropwise at a rate such that the internal temperature remains between 12-15 ${ }^{\circ} \mathrm{C}$, which took $40 \mathrm{~min}$ (Notes 10,11). The resulting white suspension is further stirred for $30 \mathrm{~min}$ at $0{ }^{\circ} \mathrm{C}$. It is then transferred into a 2-L, twonecked, round-bottomed flask before $1 \mathrm{~L}$ of cold $3 \mathrm{M}$ aqueous hydrochloric acid is added dropwise over a $30 \mathrm{~min}$ period of time (Note 12). The cooling bath is removed, and the off-white suspension is stirred for $1 \mathrm{~h}$ at room temperature. It is then filtered through a Büchner funnel. The white precipitate is washed with deionized water $(3 \times 200 \mathrm{~mL})$ (Note 13). It is spread out in a $20-\mathrm{cm}$ diameter evaporating dish and dried in an oven at 40 ${ }^{\circ} \mathrm{C}$ under $30 \mathrm{mmHg}$ vacuum until constant weight (Note 5) to afford $37.4 \mathrm{~g}$ $(81 \%)$ of $N, N^{\prime}$-dimesitylethylenediamine dihydrochloride as a white powder (Note 14).

C. 1,3-Dimesitylimidazolinium Chloride. Four 20-mL pressure vials each equipped with a magnetic stirring bar are individually charged with $N, N^{\prime}$-dimesitylethylenediamine dihydrochloride (4.62 g, $0.0125 \mathrm{~mol}, 1.0$ equiv) and triethyl orthoformate $(6.25 \mathrm{~mL}, 0.0375 \mathrm{~mol}, 3.0$ equiv) (Note 15). The mixtures are mixed with a spatula until a homogeneous thick white paste is obtained. The vials are closed with screw caps equipped with a pressure sensor and a glass inlet tube ended by a sapphire window containing an optical fiber temperature sensor. The reaction mixtures are heated for $5 \mathrm{~min}$ at $145{ }^{\circ} \mathrm{C}$ in a monomodal microwave reactor (Note 16). After cooling to room temperature, the resulting beige-yellow suspensions are combined in a $250-\mathrm{mL}$ beaker placed in an ice bath and each reaction vessel is rinsed with diethyl ether $(2 \times 12.5 \mathrm{~mL})$, which is also added to the beaker (Note 17). The beige suspension is filtered through a Büchner funnel. The white precipitate is washed with diethyl ether $(3 \times 50 \mathrm{~mL})$ (Note 17). The white precipitate is further purified by dissolution into hot acetonitrile $(50 \mathrm{~mL})$ (Note 18). The solution is allowed to cool to room temperature and then diethyl ether is added $(200 \mathrm{~mL})$ (Note 17). The resulting pale yellow suspension is filtered through a Büchner funnel. The white precipitate is 
washed with diethyl ether $(50 \mathrm{~mL})$ (Note 17). The precipitate is spread out in a 20 -cm diameter evaporating dish and dried in an oven at $40{ }^{\circ} \mathrm{C}$ under 30 $\mathrm{mmHg}$ vacuum until constant weight (Note 5) to afford $13.5 \mathrm{~g}(79 \%)$ of 1,3-dimesitylimidazolinium chloride as white microcrystals (Note 19).

\section{Notes}

1. $2,4,6$-Trimethylaniline ( $\geq 98 \%$ ) was purchased from Aldrich and used as received.

2. Reagent grade isopropyl alcohol was obtained from EMD Chemical Inc. and used without any further purification.

3. Glyoxal (ca. 40\% aqueous solution) was purchased from Aldrich and stored in a refrigerator at $+6{ }^{\circ} \mathrm{C}$.

4. A second crop of yellow precipitate formed in the filtrate upon standing at room temperature for a few hours. It was filtered through a Büchner funnel and washed with deionized water $(2 \times 50 \mathrm{~mL})$ to afford ca. $0.75 \mathrm{~g}$ of $N, N^{\prime}$-dimesitylethylenediimine ( $\mathrm{mp} 156-157^{\circ} \mathrm{C}$ ) that was added to the first crop. Upon resting overnight under the fume cupboard, the filtrate afforded a third crop of dark yellow solid (ca. $2.3 \mathrm{~g}, \mathrm{mp} 149-152{ }^{\circ} \mathrm{C}$ ) that was discarded.

5. A vacuum oven (NAPCO, Model 5831 from Cascade TEK, Oregon) was used at $40{ }^{\circ} \mathrm{C}$ under $30 \mathrm{mmHg}$ vacuum. The submitters dried the product in open air under an IR lamp.

6. Spectral and analytical data for $N, N^{\prime}$-dimesitylethylenediimine are as follows: $\mathrm{mp} 157{ }^{\circ} \mathrm{C}$; IR (ATR) 2911, 1723, 1615, 1475, 1373, 1201, 1139, 1031, 1012, 928, $850 \mathrm{~cm}^{-1} ;{ }^{1} \mathrm{H}$ NMR (400 MHz, $\left.\mathrm{CDCl}_{3}\right) \delta: 2.16$ (s, 12 $\mathrm{H}), 2.29(\mathrm{~s}, 6 \mathrm{H}), 6.91(\mathrm{~s}, 4 \mathrm{H}), 8.10(\mathrm{~s}, 2 \mathrm{H}) ;{ }^{13} \mathrm{C} \mathrm{NMR}\left(100 \mathrm{MHz}, \mathrm{CDCl}_{3}\right)$ $\delta: 18.3,20.8,126.6,129.0,134.3,147.5,163.5$; HRMS (ESI) $\mathrm{m} / z$ calcd. for $\mathrm{C}_{20} \mathrm{H}_{25} \mathrm{~N}_{2}^{+}\left([\mathrm{M}+\mathrm{H}]^{+}\right)$293.2012; found 293.2018; Anal. calcd for $\mathrm{C}_{20} \mathrm{H}_{24} \mathrm{~N}_{2}$ : C, 82.15; H, 8.27; N, 9.58; found: C, 81.98; H, 8.07; N, 9.54.

7. Tetrahydrofuran $(99+\%$, stabilized) was purchased from Acros and used without any further purification.

8. Sodium borohydride (powder, 98\%) was purchased from Aldrich and used as received.

9. The submitters note that the use of a smaller excess of sodium borohydride compared to $N, N^{\prime}$-dimesitylethylenediimine led to significantly lower yields of $N, N^{\prime}$-dimesitylethylenediamine dihydrochloride tainted with colored impurities 
10. Hydrochloric acid for analysis (ca. $37 \%$ solution in water) was purchased from Acros and used as received.

11. A strongly exothermic reaction takes place. During the addition of $\mathrm{HCl}$, the reaction temperature slowly increases to $15^{\circ} \mathrm{C}$ within $5 \mathrm{~min}$ and then is maintained between $12-15^{\circ} \mathrm{C}$ by controlling the addition rate.

12. The $3 \mathrm{M}$ hydrochloric acid was cooled in an ice bath to $0{ }^{\circ} \mathrm{C}$. The cold hydrochloric acid solution was then transferred to the dropping funnel in $50 \mathrm{~mL}$ batches and was added dropwise at such a rate that the temperature is maintained between $8-10{ }^{\circ} \mathrm{C}$. During the addition, hydrogen is evolved and frothing occurs.

13. A second crop of white precipitate formed in the filtrate upon standing at room temperature for a few hours. It was filtered through a Büchner funnel and washed with deionized water $(2 \times 50 \mathrm{~mL})$ to afford ca. $0.6 \mathrm{~g}$ of $N, N^{\prime}$-dimesitylethylenediamine dihydrochoride $\left(\mathrm{mp} 224-225{ }^{\circ} \mathrm{C}\right.$ $(\mathrm{dec}))$ that was added to the first crop.

14. Spectral and analytical data for $N, N^{\prime}$-dimesitylethylenediamine dihydrochloride are as follows: $\mathrm{mp} 224-225{ }^{\circ} \mathrm{C}$ (dec); IR (ATR) 3424, 3254, 2961, 2917, 2660, 2470, 2355, 1668, 1607, 1563, 1470, 1388, 1304, 1219, 1200, 1190, 1136, 1034, 980, 900, 875, $851 \mathrm{~cm}^{-1}$; ${ }^{1} \mathrm{H}$ NMR (400 MHz, DMSO- $\left.d_{6}\right) \delta: 2.25(\mathrm{~s}, 6 \mathrm{H}), 2.48(\mathrm{~s}, 12 \mathrm{H}), 3.71(\mathrm{~s}, 4 \mathrm{H}), 6.99(\mathrm{~s}, 4 \mathrm{H}) ;{ }^{13} \mathrm{C}$ NMR (100 MHz, DMSO- $\left.d_{6}\right) \delta: 17.9,20.1,45.8,130.1,131.4,132.5,137.0$; HRMS (ESI) $\mathrm{m} / z$ calcd. for $\mathrm{C}_{20} \mathrm{H}_{29} \mathrm{~N}_{2}{ }^{+}\left([\mathrm{M}-\mathrm{H}-2 \mathrm{Cl}]^{+}\right)$297.2325; found 297.2331; Anal. calcd. for $\mathrm{C}_{20} \mathrm{H}_{30} \mathrm{Cl}_{2} \mathrm{~N}_{2}$ : C, 65.03; $\mathrm{H}, 8.19 ; \mathrm{N}, 7.58$; found: C, 65.94; H, 8.69; N, 7.63.

15. Triethyl orthoformate (98\%) was purchased from Aldrich and used as received.

16. An INITIATOR @Biotage, Serial No. 10662-17U Microwave reactor was employed. The maximum microwave power was set at $120 \mathrm{~W}$ and the pressure limit at 250 psi (17 bar). No ramp and no simultaneous cooling were applied. The submitters performed the microwave reaction in a single $80-\mathrm{mL}$ pressure vial equipped with a magnetic stirring bar using a Discover ${ }^{\circledR}$ LabMate instrument (CEM Corp., Matthews, NC). The maximum microwave power was set at $120 \mathrm{~W}$ and the pressure limit at 250 psi (17 bar). No ramp and no simultaneous cooling were applied.

17. Reagent grade diethyl ether was obtained from Fisher Chemical and used without any further purification.

18. HPLC grade acetonitrile was obtained from EMD Chemicals Inc. and used without any further purification. 
19. Spectral and analytical data for 1,3-dimesitylimidazolinium chloride: $\mathrm{mp} 279-281{ }^{\circ} \mathrm{C}$ (dec); IR (ATR) 3642, 3348, 3213, 2848, 1623, $1484,1448,1383,1274,1216,1038,869,846 \mathrm{~cm}^{-1}$; ${ }^{1} \mathrm{H}$ NMR $(400 \mathrm{MHz}$,

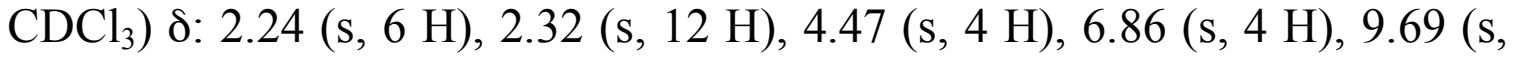
$1 \mathrm{H}) ;{ }^{13} \mathrm{C}$ NMR $\left(100 \mathrm{MHz}, \mathrm{CDCl}_{3}\right) \delta: 17.9,20.9,51.7,129.7,130.3,134.9$, 139.9, 160.1; HRMS (ESI) $\mathrm{m} / z$ calcd. for $\mathrm{C}_{21} \mathrm{H}_{27} \mathrm{~N}_{2}{ }^{+}\left([\mathrm{M}-\mathrm{Cl}]^{+}\right) 307.2169$; found 307.2177; Anal. calcd. for $\mathrm{C}_{21} \mathrm{H}_{27} \mathrm{ClN}_{2}$ : C, 73.56; H, 7.94; N, 8.17; found: C, 71.68; H, 8.19; N, 7.92.

\section{Safety and Waste Disposal Information}

All hazardous materials should be handled and disposed of in accordance with "Prudent Practices in the Laboratory"; National Academy Press; Washington, DC, 1995.

\section{Discussion}

Imidazolinium salts are the most common synthetic precursors for generating saturated $N$-heterocyclic carbenes (NHCs), a new class of stable divalent carbon species that has already afforded a wealth of nucleophilic reagents, organocatalysts, and organometallic complexes, including optically active compounds. ${ }^{2}$ In particular, deprotonation of 1,3-dimesitylimidazolinium chloride with a non-nucleophilic strong base gives direct access to the important NHC nicknamed SIMes or $\mathrm{H}_{2}$ IMes that serves as an ancillary ligand in the second generation Grubbs and Hoveyda-Grubbs metathesis catalysts, among other uses. ${ }^{3}$

The preparation of imidazolinium salts is usually achieved via condensation of an $N, N^{\prime}$-disubstituted ethane-1,2-diamine and an inorganic ammonium salt with a triethyl orthoester in the presence of a catalytic amount of formic acid. ${ }^{4}$ Alternatively, a suitable ethane-1,2-diammonium salt may be used as a single starting material for the heterocyclic cation and its counteranion. In all cases, the orthoester serves both as a solvent and a reagent. Numerous variations of this experimental procedure have been reported in the literature..$^{5}$ All of these reactions require prolonged heating under reflux conditions in order to reach satisfactory conversions. Thus, reaction times ranging between a few hours and a few days are commonly encountered, unless ethanol is distilled off the reaction medium to drive the cyclization more rapidly to completion. ${ }^{6}$ 
Microwave-assisted organic synthesis (MAOS) has received increasing attention in recent years as a valuable technique for accelerating chemical reactions. $^{7}$ The development of safe and reliable mono- or multimodal microwave reactors specifically designed for chemical applications has significantly reinvigorated time-honored laboratory practices. Condensation reactions leading to heterocyclic products are particularly effective under microwave irradiation conditions. ${ }^{8}$

In 2006, we disclosed a very simple and efficient procedure for the microwave-assisted synthesis of 1,3-diarylimidazolinium chlorides by cyclocondensation of $N, N^{\prime}$-diarylethane-1,2-diamine dihydrochlorides with triethyl orthoformate (Table 1). ${ }^{9}$ The methodology was further extended to prepare a wide range of imidazolinium and tetrahydropyrimidinium salts bearing diverse aromatic and aliphatic substituents on the nitrogen and carbon atoms of the cyclic amidinium function. In these experiments, recourse to an amine free base together with an inorganic ammonium salt as starting materials provided an easy way to vary the nature of the counterion (Table 2). ${ }^{10}$ Indeed, bulky polyatomic anions such as $\mathrm{BF}_{4}^{-}, \mathrm{PF}_{6}^{-}, \mathrm{TfO}^{-}$, or $\mathrm{Tf}_{2} \mathrm{~N}^{-}$could be introduced directly using readily available ammonium salts, thereby eliminating the need for subsequent ion exchange.

The procedure described above is a preparative-scale application of our methodology starting from simple, commercially available reagents. Prior to the microwave-assisted cyclization, it involves the formation of $N, N^{\prime}$-dimesitylethane-1,2-diamine dihydrochloride via condensation of glyoxal with two equivalents of mesitylamine, followed by reduction of the intermediate Schiff base with sodium borohydride under acidic conditions. All three steps proceed readily under normal atmosphere. Laboratory grade solvents and reagents taken straight from the bottles do not require any additional purification. The two intermediates and the final product are isolated in high yield and purity by simple filtration and washing and may be used without any further purification for most applications. 
Table 1. Microwave-assisted synthesis of 1,3-diarylimidazolinium chlorides. ${ }^{9}$

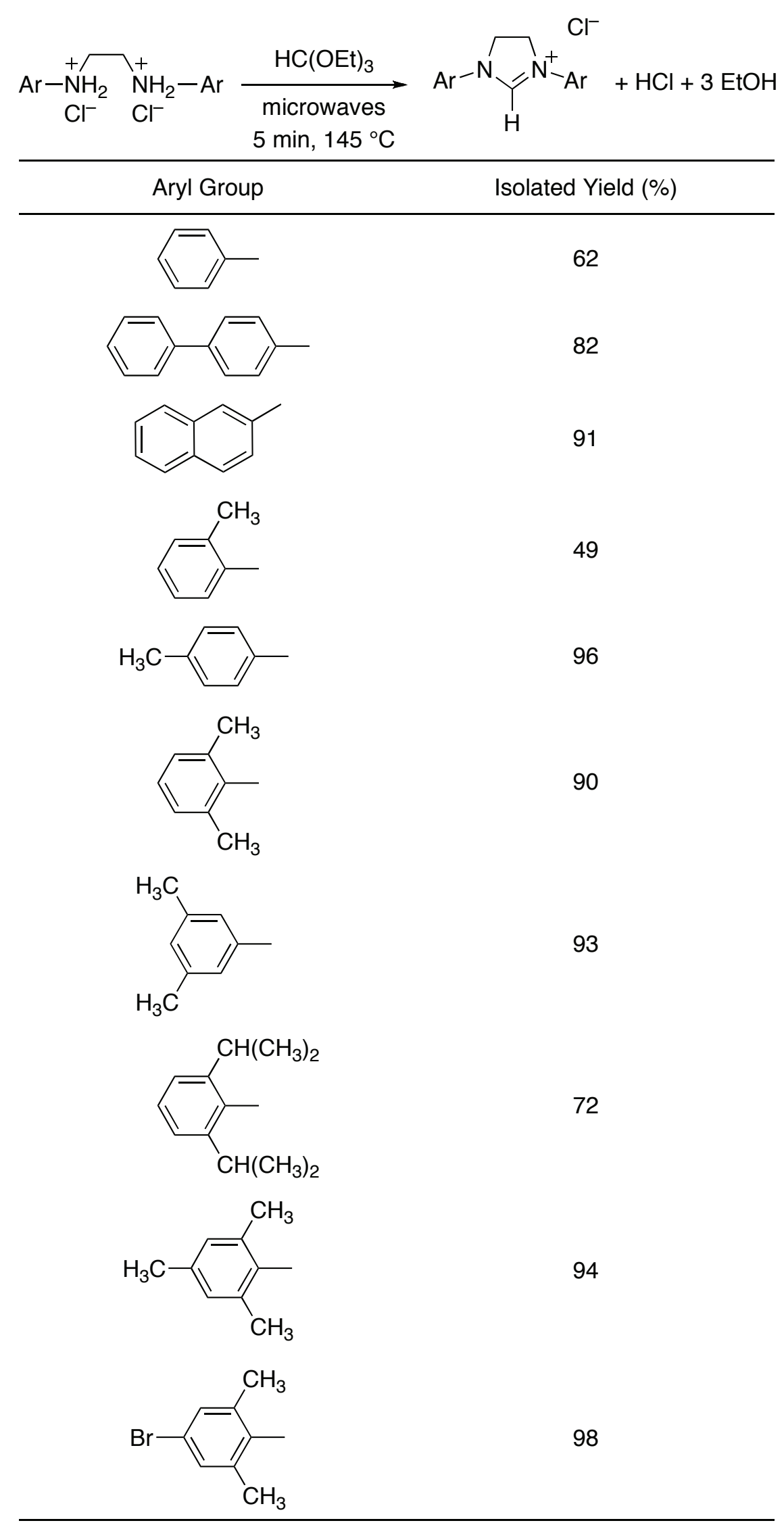


Table 2. Microwave-assisted synthesis of cyclic amidinium salts. ${ }^{10}$

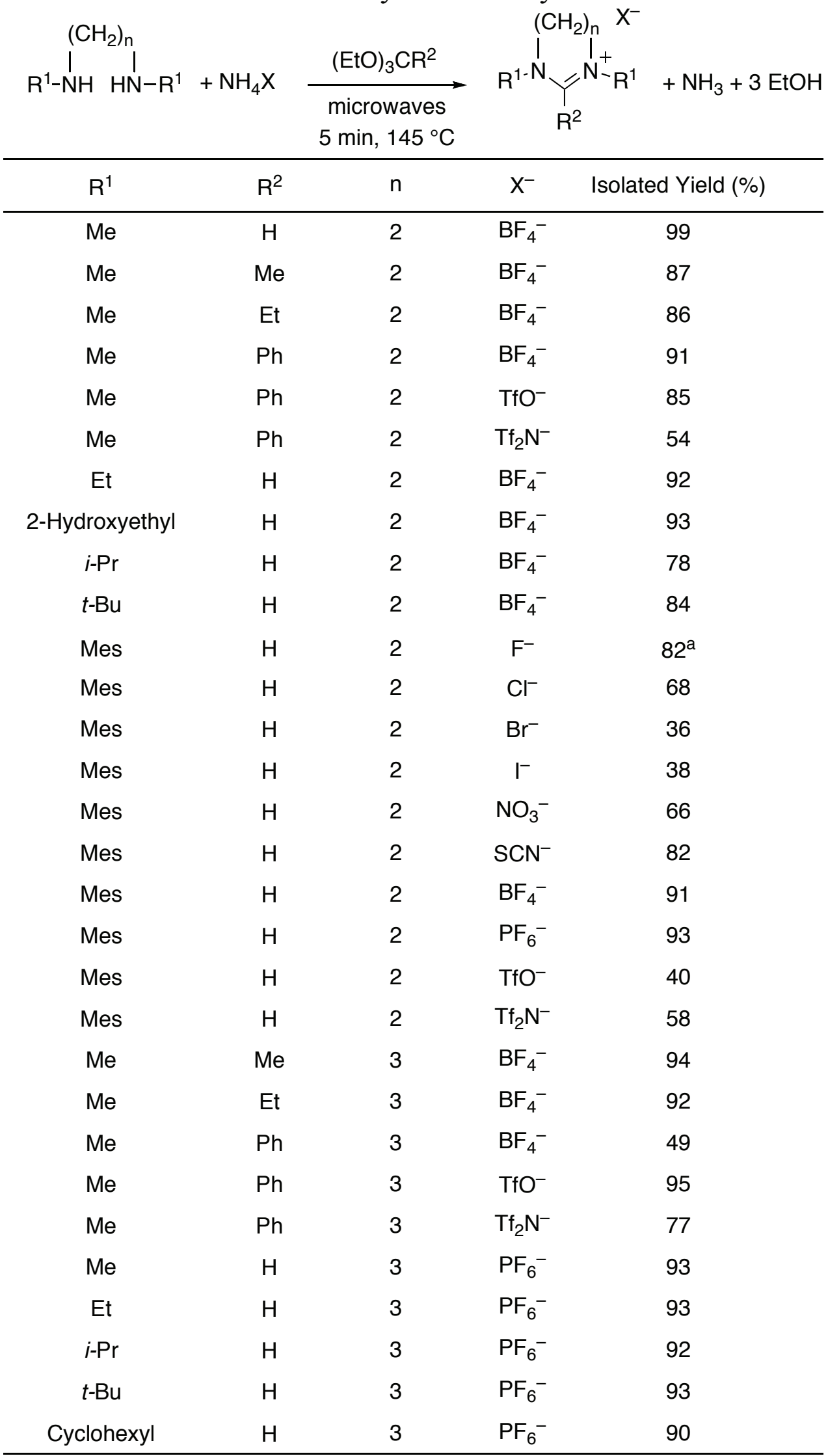

a Starting from $N, N^{\prime}$-dimesityl-1,2-ethanediamine dihydrofluoride. 
1. Department of Chemistry, University of Liège, Sart-Tilman par 4000 Liège, Belgium (email: 1.delaude@ulg.ac.be).

2. (a) Carbene Chemistry: From Fleeting Intermediates to Powerful Reagents; Bertrand, G., Ed.; Marcel Dekker: New York, 2002. (b) NHeterocyclic Carbenes in Synthesis; Nolan, S. P., Ed.; Wiley-VCH: Weinheim, 2006. (c) N-Heterocyclic Carbenes in Transition Metal Catalysis; Topics in Organometallic Chemistry, Vol. 21; Glorius, F., Ed.; Springer: Berlin, 2007.

3. (a) Scholl, M.; Ding, S.; Lee, C. W.; Grubbs, R. H. Org. Lett. 1999, 1, 953-956. (b) Garber, S. B.; Kingsbury, J. S.; Gray, B. L.; Hoveyda, A. H. J. Am. Chem. Soc. 2000, 122, 8168-8179.

4. Saba, S.; Brescia, A.; Kaloustian, M. S. Tetrahedron Lett. 1991, 32, 5031-5034.

5. See, for example: (a) Arduengo, A. J., III; Krafczyk, R.; Schmutzler, R.; Craig, H. A.; Goerlich, J. R.; Marshall, W. J.; Unverzagt, M. Tetrahedron 1999, 55, 14523-14534. (b) Delaude, L.; Szypa, M.; Demonceau, A.; Noels, A. F. Adv. Synth. Catal. 2002, 344, 749-759. (c) Ma, Y.; Song, C.; Jiang, W.; Wu, Q.; Wang, Y.; Liu, X.; Andrus, M. B. Org. Lett. 2003, 5, 3317-3319. (d) Funk, T. W.; Berlin, J. M.; Grubbs, R. H. J. Am. Chem. Soc. 2006, 128, 1840-1846.

6. See, for example: (a) Alder, R. W.; Blake, M. E.; Bufali, S.; Butts, C. P.; Orpen, A. G.; Schütz, J.; Williams, S. J. J. Chem. Soc., Perkin Trans. 1 2001, 1586-1593. (b) Van Veldhuizen, J. J.; Gillingham, D. G.; Garber, S. B.; Kataoka, O.; Hoveyda, A. H. J. Am. Chem. Soc. 2003, 125, 12502-12508.

7. (a) Microwaves in Organic and Medicinal Chemistry; Kappe, C. O.; Stadler, A., Eds.; Methods and Principles in Medicinal Chemistry, Vol. 25; Wiley-VCH: Weinheim, 2005. (b) Microwave Assisted Organic Synthesis; Tierney, J. P.; Lidström, P., Eds.; Blackwell: Oxford, 2005. (c) Microwaves in Organic Synthesis; 2nd ed.; Loupy, A., Ed.; WileyVCH: Weinheim, 2006.

8. For a review, see: Xu, Y.; Guo, Q.-X. Heterocycles 2004, 63, 903-974.

9. Aidouni, A.; Demonceau, A.; Delaude, L. Synlett 2006, 493-495.

10. Aidouni, A.; Bendahou, S.; Demonceau, A.; Delaude, L. J. Comb. Chem. 2008, 10, 886-892. 


\section{Appendix}

\section{Chemical Abstracts Nomenclature; (Registry Number)}

Mesitylamine: Benzenamine, 2,4,6-trimethyl-; (88-05-1)

Glyoxal: Ethanedial; (107-22-2)

$N, N^{\prime}$-Dimesitylethylenediimine: Benzenamine, $N, N^{\prime}$-1,2-ethane-

diylidenebis[2,4,6-trimethyl-; (56222-36-7)

Sodium borohydride: Borate(1-), tetrahydro-, sodium; (16940-66-2)

$N, N^{\prime}$-dimesitylethylenediamine dihydrochloride: 1,2-Ethanediamine,

$N, N^{\prime}$-bis(2,4,6-trimethylphenyl)-, dihydrochloride; (258278-23-8)

Triethyl orthoformate: Ethane, 1,1',1"-[methylidynetris(oxy)]tris- ; (122-51-0)

1,3-Dimesitylimidazolinium Chloride: $1 H$-Imidazolium, 4,5-dihydro-

1,3-bis(2,4,6-trimethylphenyl)-, chloride (1:1); (173035-10-4)

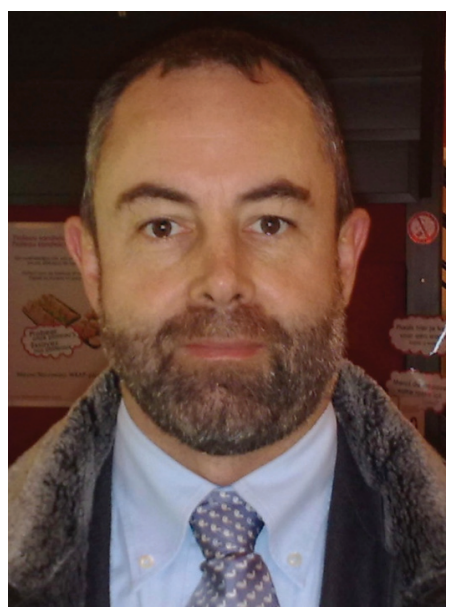

Lionel Delaude was born in 1966 in Huy, Belgium. He received his Ph.D. from the University of Liège, Belgium under the supervision of Pierre Laszlo. After postdoctoral research at the University of Ottawa, Canada with Howard Alper and at Columbia University in the City of New York with Ronald Breslow, he returned to Liège where he is presently appointed as a Senior Lecturer within the Center for Education and Research on Macromolecules (CERM). His current research interests focus on the design of new ruthenium- $N$-heterocyclic carbene complexes for catalytic applications.

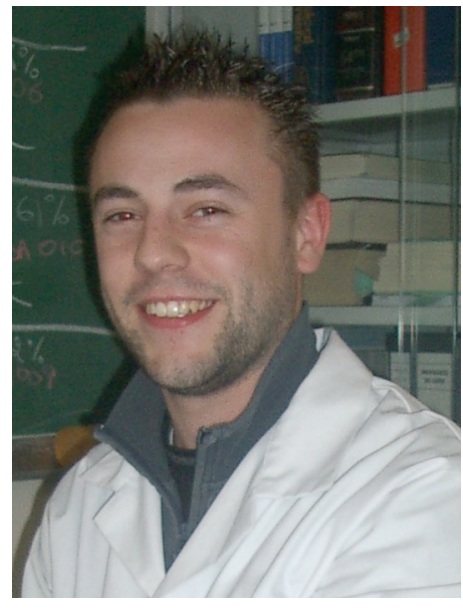

Morgan Hans was born in 1985 in Malmedy, Belgium. He received his M.Sc. degree in chemistry in 2009 from the University of Liège and is currently pursuing a Ph.D. in organometallic chemistry at the University of Liège under the supervision of Lionel Delaude, working on the synthesis and catalytic applications of new zwitterions derived from $N$-heterocyclic carbenes. 


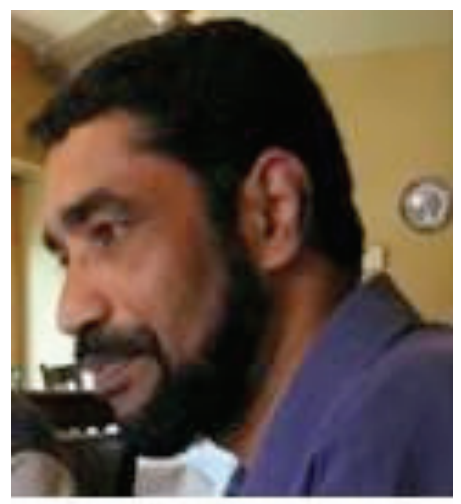

Somenath Chowdhury grew up in Majirdanga, India. He obtained his M.Sc. degree in Chemistry from the Indian Institute of Technology, Kharagpur, India and his Ph.D. degree from the University of Saskatchewan, Canada. In his Ph.D. research he worked on the design and synthesis of peptide beta sheet mimics under the supervision of Professor Heinz-Bernhard Kraatz. After finishing his Ph.D. he carried out research with Professor Giuseppe Melacini's group at McMaster University, Canada for one and a half years where he studied protein ligand interactions by NMR spectroscopy. He then joined Professor Jonathan Ellman's lab at the University of California, Berkeley in Sept 2008 as an NSERC postdoctoral fellow. His current research focuses on developing small molecule protease inhibitors. 